\title{
An Research on Cultivating Method of College Students' Online Learning Ability
}

\author{
WenGuang Li, XinHui Wang, and MingMei Yu
}

\begin{abstract}
With the rapid development of the information technology and network technology, multimedia and network has been used in education process more and more common. The characteristics of students' online learning behavior have important significance on online learning. However, what are the characteristics of students' online learning behavior and how they affect the online learning. Now, relevant research is still relatively small. Based on literature and surveys, we use spss and excel to count and analyze data. We try to describe the behavior of students and explain the inherent characteristics. Finally, based on the information ability, independent learning ability, collaborative learning ability, metacognitive and creativity; we summarize several strategies of cultivating students' online learning ability.
\end{abstract}

Index Terms—online learning ability, online learning behavior, e-learning, survey.

\section{INTRODUCTION}

With the rapid development of the information technology and network technology, multimedia and network has been used in education process more and more common. Use of network resources to get information and learning is a must master skill. However, the traditional learning methods and strategies have cannot adapt to online learning environment, while the new strategy, new methods are not completely established. Then, many students do not know what should they do and how to do in online learning environment. Meanwhile, lack of teachers and parents monitor, students cannot good control own study, learning effect of online environment is not good.

A learner is the main of learning; online learning has become an important way of human lifelong learning. In the reform of education background, network education of college students is daily is an important content and component. So study on college students' learning behavior of online ideas, ways and skills and adaptability ,grasps the online learners' learning behavior rule, it is great help to promote college students effective online learning, suitable for the development of the university students' network education platform, resources etc . This will help students to explore and develop modern education technology using network education, construct a fully embody the characteristics of university students' network learning

Manuscript received March 14, 2011.

F.A. Author is with the Normal College , Shenzhen University, WenGuang Li, Shenzhen,China (e-mail: liwg@szu.edu.cn).

S.B. Author is with the Normal College, Shenzhen University, XinHui Wang, Shenzhen, China (e-mail: xinhui851110@gmail.com).

T.C. Author is with Faculty of Education, University of Hongkong, MingMei Yu, Hongkong ,China (e-mail: mmyu@hku.hk). individualized education teaching mode, to leading teaching and students' autonomous learning network, promote the university student information literacy training, lifelong learning ability, give full play to the function of network education[2].

Therefore, we think it necessary to get online learners as study object, the behavior of the learner as key points. Analysis of online learning behavior of learners, we summarize several strategies of cultivating students' online learning ability.

\section{BACKGROUND}

New technical generation will influence on education, and network influence extremely impressive. Due to network learning its benefits, more and more people choose network as one kind of study way, but it is a new style of learning, although have all kinds of benefits, but premise condition is you can participate in online learning with network learning needs of the various ability. We should have the following learning ability.

1) Information ability. Search information ability. In online learning, culture is one of the characteristics of selecting function is information of great capacity and range, content more, the quick pace. Therefore, in the network, information is inexhaustible. But, learners need solves the problem of how to the most economical, the most timesaving way to discover related information. Therefore, students must master certain information searching ability. Judge information ability. In a number of information, what information is learning needs most, what information about learning task is useful, what information is correct, the need for information students through the evaluation to secure their required information, and this is very important for online learning. Students must master certain electronic document, network resources of production capacity, and how to make the online information collection down and how to use them.

2) Independent learning ability. Independent learning ability is a kind of studying books and learning practice skill ability, including self choice, setting goals, customized content, choose study methods and ways and self management learning process, etc. First, learners should bosom friend, namely the attention and to understand their own level, Secondly, judgment and feedback, judge the things that he had done right and wrong, and produce certain feedback information and certain disciplinary actions. This ability plays a decisive role in online learning. Especially used to being teachers encourage, students must have this ability can better into the network learning. 
3) Collaborative learning ability. Online learning, emphasize more cooperative learning, one of the most basic requirement to realize collaborating study is has certain communication skills. In addition to their own quality outside, grasps some tools is necessary. The interaction between teacher and students, it can train students' team spirit.

4) Metacognitive. Metacognitive is individual on their own cognitive activities of self-awareness, self-experience, the self-adjustment. Learning activities is not only for the identification, learned material processing and finishing process, but also for the process of active monitoring, adjusting their learning activity of thinking process. Cognitive can make learners effective reflection, evaluation and direct know all kinds of activities, supervision and learners' learning process. Therefore metacognitive in online learning is indispensable.

5) Creativity. The 21st century and the future of knowledge economy and society will develop in the high quality, creative talents of the huge demand, innovation depends on a country and national comprehensive strength and competitive power. Based on network technology study, then students can better adapt to the needs of the informational society. And as a kind of network-based learning, it requires students have better creative thinking.

\section{PROCEDURES}

From June to September, this study selected 200 students from Shenzhen University by random sampling. Considering the research is to study the behavior of learning, we choose the main learning area: library and teaching building. This questionnaire is written by the form of edition, issued 200 questionnaires, recycled 200 questionnaires, 174 valid questionnaires, recovery is $100 \%$ and efficient is $100 \%$. The respondents are from arts and science. It is 80 male, 94 female, 18 freshmen, 22 sophomores, 14 juniors, 24 seniors; the first year of postgraduates 51, the second year of postgraduates, the third year of postgraduates. And recoveries of questionnaires by our team members are personally done.

Through literature review, and exchange of student and experts, we set eight dimensions to examine online learning behaviors of students:

1) The basic situation of using the network with students

2) The equipment, premises of students use the network

3) Knowledge of students on the online learning situation

4) Teacher-student relations in online learning and communication

5) The study habits, learning strategies and harvesting of online learning

6) The evaluation and incentives of online learning

7) Categories of online learning resources and practices with students favor

8) Online learning problems

Depth analysis of online learning behavior information from the characterization of the behavior of the occurrence and development of internal factors, the nature of online learning behavior and status types, the association between each state, combined. Thus we propose the insights and strategies for promotion of students' online learning.

\section{RESUlTS AND DISCUSSION}

We used social science software SPSS and EXCEL software to descriptive statistics and analysis survey data.

\section{A. The basic situation of using the network with students}

Using network is the necessary elements for students to learn online. In the survey, 145 students (83\%) often use the Internet, 25 people sometimes use Internet, only four basic don't use the Internet. Therefore, college students is a universal network for the college students, it is a foundation of online learning. Most students surf the Internet every day time in 2-4 hours or even more than 4 hours, However, in a few hours, students should use within the network, communication tool for far more than previous television, radio, newspapers and magazines, books materials provided by the traditional media information, they become the main source of information. We can see that the students in the process of using network, what has been done. In the process, the use of Internet contact among college students is mainly about all kinds of information, chatting, entertainment and leisure, game and network application study only $22 \%$. Thus, promoting college students reasonable use online learning network, we still need more effort.

TABLE I. USING TIME, INFORMATION SOURCE, PURPOSE OF STUDENTS

\begin{tabular}{|c|c|c|c|c|}
\hline \multirow{2}{*}{ time } & $\mathbf{0 - 1}$ hour & $\mathbf{1 - 2}$ hours & $\begin{array}{c}\mathbf{2 - 4} \\
\text { hours }\end{array}$ & $\begin{array}{c}\text { more than 4 } \\
\text { hours }\end{array}$ \\
\cline { 2 - 5 } informati & $7 \%$ & $26 \%$ & $33 \%$ & $34 \%$ \\
\hline \multirow{2}{*}{ on source } & $\begin{array}{c}\text { television } \\
\text { radio }\end{array}$ & $\begin{array}{c}\text { newspapers } \\
\text { and } \\
\text { magazines }\end{array}$ & books & $\begin{array}{c}\text { network, } \\
\text { communicatio } \\
\text { n tool }\end{array}$ \\
\cline { 2 - 5 } purpose & $3 \%$ & $3 \%$ & $17 \%$ & $77 \%$ \\
\hline \multirow{2}{*}{ chatting } & entertainment & study & $\begin{array}{c}\text { Information } \\
\text { query }\end{array}$ \\
\cline { 2 - 5 } & $31 \%$ & $27 \%$ & $22 \%$ & $20 \%$ \\
\hline
\end{tabular}

\section{B. The equipment, premises of students use the network}

Dormitory (family) is the main network of students; it is more than 60 percent. But the reaching computer room provide by university for students is only $19 \%$. As a specialized computer teaching for students to use of network, but was it so cold, why? How to play the role of teaching computer to promote students use it for online learning?

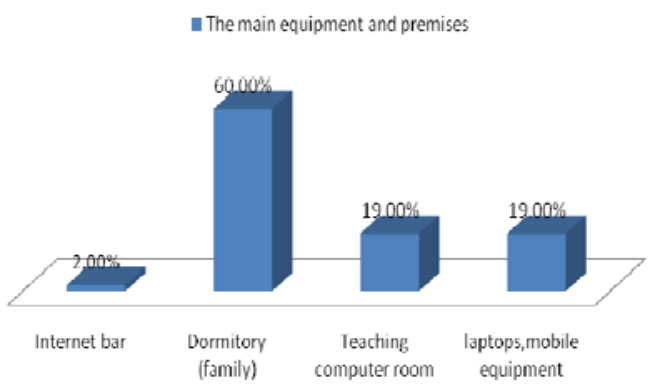

Figure 1. The main equipment and premises

\section{Knowledge of students on the online learning situation}

In the survey, students can actively, frequent use of the Internet and television and other modern learning tools for learning is not much, accounted for only $23 \%$. This may 
relate to students' interest in learning to online, data shows great interest in online learning to $7 \%$, for a greater interest in 39, no more than half. Moreover, most students to think the help for learning by network is normal, Proportion 63\%. 56 percent of students improve their learning efficiency; even there has a fraction of students think it is obstacles.

TABLE II. KNOWLEDGE OF STUDENTS ON THE ONLINE LEARNING

\begin{tabular}{|c|c|c|c|c|}
\hline \multirow{2}{*}{ frequency } & often & sometimes & \multicolumn{2}{|c|}{ rarely } \\
\cline { 2 - 5 } & $23 \%$ & $59 \%$ & \multicolumn{2}{|c|}{$18 \%$} \\
\hline \multirow{2}{*}{ interest } & great & good & A little & none \\
\cline { 2 - 5 } & $7 \%$ & $39 \%$ & $47 \%$ & $7 \%$ \\
\hline \multirow{2}{*}{$\begin{array}{c}\text { The help } \\
\text { for learn }\end{array}$} & great & good & A little & none \\
\cline { 2 - 5 } & $9 \%$ & $21 \%$ & $63 \%$ & $7 \%$ \\
\hline $\begin{array}{c}\text { The } \\
\text { influence } \\
\text { of the } \\
\text { learning } \\
\text { efficiency }\end{array}$ & great & good & A little & none \\
\cline { 2 - 5 } & $17 \%$ & $55 \%$ & $23 \%$ & $5 \%$ \\
\hline
\end{tabular}

College students are the main application network era, is the most likely to accept new things, like new things. They understand, accept the new thing is a rational process. Let student into the online study, recognize online learning, we must let them know online learning relative to traditional learning advantages, training, online learning interest in network operation skill, using the Internet for learning services. As the chart shows, most of the students are thought to online learning from the form to the contents are suitable for college students' learning, but the learning quality and low efficiency, content is not rich and practical, but a few students think network learning too free, is not practical, not suitable for learning.

What are the reasons of online learning success? Students generally think of online learning effect between the main reasons lies in the learners with ability, and subjective intention is the key factor to their level. Only clear of subject status, center position, rely on their own efforts to better fulfill the tasks, obtain good effect of online learning.

- the contents are suitable for college students' learning

- Learning function stronger, but learning quality and efficiency is low - Form free, but study content is not enough enriched and practical

- Too much liberty, practical, not suitable for learning

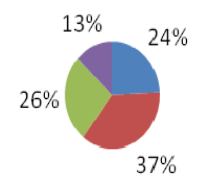

Figure 2. Compare the traditional learning and online learning

\section{Teacher-student relations in online learning and communication}

Although the students is the most important in online learning, but the self effort extent of interaction between teachers and students is also the crucial factor. In the poll, most of the teachers and classmates think online learning should be equal. Although it is online learning, but due to the long-term online learning traditional teaching effect, the majority of the students (68\%) are need teachers' help.

The rapid developments of network technology, college students are quickly grasp the latest Internet technology group. One of the real-time communication network communication tools for online learning is the student main selection, number by 50\%. But not for exchange of real-time communication and BBS E-mail communication, they doesn't like very much. Students and teachers of online learning communication most still appear in reality, students tend to be in the reality and the teacher's exchange activities. While online learning process with the teacher as the communication consultation related problems, pay attention to the teacher exam content, teaching plan, log and reply to the teacher, and teachers of active two-way communication accounted for only $15 \%$.
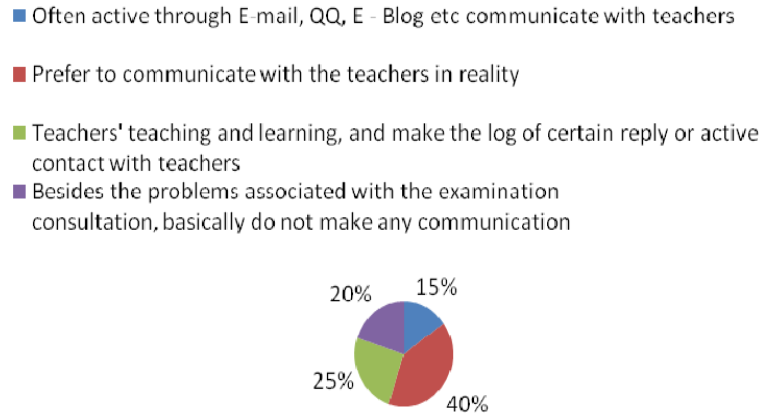

Figure 3. Communicate with the teachers

When Teachers' online FAQ, students do not active participate. More than 70\% students think it is no useful and communicate with teachers rarely. Some classmates actively raise the question to answer or actively search related information to answer others questions, but most students (70\%) or can answer but ignore, or simply ignored the initiative of learning exchanges. These show that college students are not good at learning and cooperative learning group, and other subjects in the group of communication, communication, not to touch, learning motivation, evaluation and feedback information is not complete, comprehensive, unfavorable effects of online learning

\section{E. The study habits, learning strategies and harvesting of online learning}

When encountered in online learning levels, most students can actively change the learning methods, strategies, and to overcome difficulties, adopt various ways to effective learning. When students in learning, meet most students to think actively taking solution and in various ways. Using network interactive way of looking for answers, actively utilize the network, which is one kind of affirmation of online learning. There is a choice to solve and through the classroom and independent study group discussion resolved, as personal subjective initiative, using their own knowledge, actively cooperating with others, to solve the problem.

Online learning process, students are mostly have mastered learning ability, making a study plan, take different learning strategies in learning network, constantly ask yourself for learning method, curriculum content, but exist obvious traditional teaching of shadow, step-by-step. In the process of learning, materials is written and network resources. Thus, the student is depend on traditional ways of learning, learning resources on the network, the use of resources and for online learning to accept.

Knowledge is still the most important online learning organization in the harvest, this also is the most fundamental 
human learning behavior of online learning behavior, modern, emerging as a way of learning, and the basic purpose of learning is the same, but also obtain knowledge of a kind of effective method.

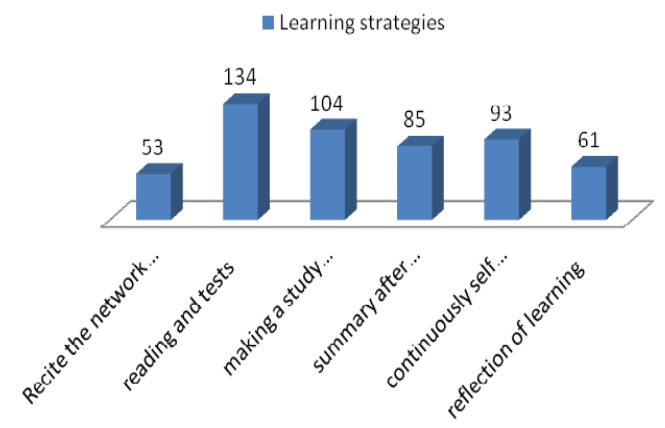

Figure 4. Learning strategies

\section{F. The evaluation and incentives of online learning}

Students hope to get a different appraisal with traditional teaching in, they pay attention to in the process of learning, participation in the collective learning process by self, acquiring knowledge. Give students the correct evaluation and incentive, can do a better job of helping students learning, learning, arouse their interest in learning, improve their learning initiative, promote the process of learning to twice the result with half the effort effect of learning.

The most motivation students wanted is target, cooperative learning in mutual cooperation, competing with each other, cooperation and competition motivation, feedback incentive. Students have the initiative, have a clear goal; the study can use to motivate you with others, and hope of cooperation and competition, hope to get others in study of evaluation, guidance and coordination with other discussion, as learning partners and competitors, mutual encouragement, cooperative learning, and make progress together.

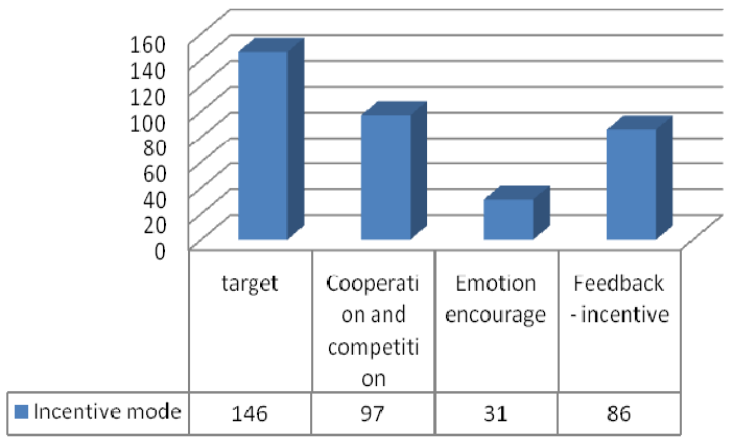

Figure 5. Incentive mode

\section{G. Categories of online learning resources and practices} with students favor

Learning resources category can stimulate students' interest in learning, the majority of students believe in online learning resources can best video form, to understand teaching content is more effective. Second are the texts and web forms, and cartoon type courseware and let students, which may in college students' mental maturity levels. But students get online learning resources from the main ways of search engines and website, and neither of the blog, BBS, when such communications group is not particularly like that network learning resources to close to the students majoring in need, for students to provide authoritative, convenient teaching resources, on the other hand also shows that students learning process in network with the main body does not pay attention to the communication between the exchange of learning, ignoring the help.

n Text, form, web form etc = audio, video m Cartoon multimedia courseware

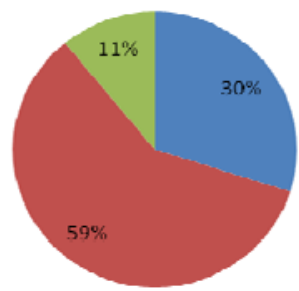

Figure 6. The best form of learning resources

Although the school every year in the investment of funds of campus network and resources construction. However, the survey, most of the students in the campus network or think learning resources on campus, and not abundant theses online learning resource use, even more students don't use. Explain to strengthen the construction of campus net resources for learning resources, and make the promotion, to guide the students to use, students learn more about campus network resources and resource efficiency, has become an important part of college students' learning material, is a very important work

\section{H. Online learning problems}

Online learning process of interaction with the most is not seasonable, communication, and the lack of authority, and often difficult, right at the start of the orderly slowly towards desultorily. Online communication with sudden, uncertainty and characteristics of virtual sex, can only rely on equipment, communication form and inflexible, not human, lets the student exchange loss caused by communication, boring, communication, thereby reach the inertia of online learning communication.

For students, primary problem is the lack of learning methods, network guide online learning process, and effective control network operation. It is learners, and network technology not skilled in learning process of interaction with the lack of communication, don't know who else to turn to.
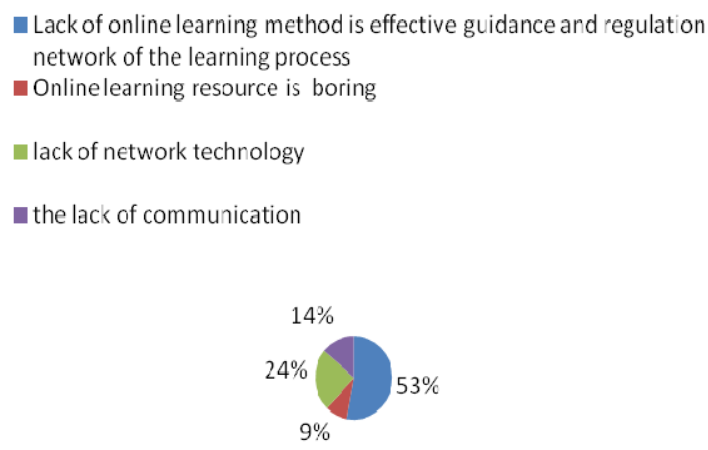

Figure 7. The problem of online learning

\section{CONCLUSIONS}

Inductive learning behavior characteristics of college students, it is having important significance for promoting 
our online teaching and learning resources construction. We summarize several strategies of cultivating students' online learning ability from information ability, independent learning ability, collaborative learning ability, metacognitive and creativity.

\section{A. Cultivating of information ability}

Through the information technology and curriculum integration, it can raise the student information ability. In this system, the information technology and curriculum integration is a learning carrier, take information technology as tools and methods to penetrate into other disciplines curriculum teaching process, to cultivate students' comprehensive ability of solving discipline problems. Computer and network and multimedia technology is the core of information technology as their real teaching tools, emphasized teacher, the most important task does not lie in the development software, but how in the teaching application software, and how the computer and network such as whole modern information technology in the teaching process of organic component integrated into the teaching process. student use the computer and network technology and multimedia technology to help them learn other disciplines, and cultural knowledge to development of their intelligence, cultivate their creation ability, to achieve high quality to complete the course teaching task, and to cultivate and improve the students' information ability.

\section{B. Cultivating of independent learning ability}

No matter from teaching regularity and teaching mode, teaching contents and teaching methods, multimedia teaching system has great advantage to cultivate and improve students' independent learning ability. Modern information technology created favorable conditions for constructing new education model it is useful to cultivate and improve students' independent learning ability. The application of modem information technology, changed the students to know things process, changed some teaching principle, changed the teaching contents and teaching material forms, changed the teaching process of the teachers and students, teaching materials and their relationship, and make the the basic elements of teaching process increase to four. Computer teaching can produce by the students of the non-linear control found type learning environment, it is more benefit at the students' autonomous explore study, cultivate independent learning ability. Therefore, to cultivate and improve students' independent learning ability, it must use of modern information technology to reform teaching process. Through discussing the relation of teachers and students, teaching content and teaching media, to make them mutual connection, interaction, forming an organic whole, establish the reasonable relatively stable pattern of classroom teaching and to optimize the education information transmission process.

\section{Cultivating of collaborative learning ability}

"Learning to collaborative" is one of the cores of contemporary education spirit. Especially the application of network learning age, cooperation spirit is very important; the ability of collaborative is an important symbol of the students' learning ability. In network environment, teachers create conditions to organize the student to carry on the cooperative learning; it is an important way to cultivate students' collaborative ability. Collaborative learning is through team or group of students. Create a collaborative environment, is the guarantee conditions to effectively train students collaborative learning ability. Create collaborative learning environment, the teacher must respect the student's personality, feelings and opinions, believe that students' self development and students' potential. Good relationship between teachers and students is a kind of important instructional strategies. It is important to Form an authentic, accept, comprehend the classroom psychology atmosphere, enables the student to participate in the freedom of expression, freedom, promoting students' confidence. Design flexibility of collaborative learning activities, to keep the form of cooperative learning activities, stimulate the novelty of the cooperative learning motivation is very important. In network support environment, it can create more abundant collaboration tools and collaborative learning environment session, interactive forms and methods, learning situation more new. It can provide important conditions to arouse learners to participate in collaboration activities motivation.

\section{Cultivating of metacognitive}

Cognitive strategies mainly include access to information strategy and processing information strategy. Cognitive strategies of learning and general knowledge learning has distinct characteristics that only by teachers teach is cannot be taught, must let students through practice experience, insight, summary, generalization, to know and learn to learn from the cognitive sublimation process. Use "mission driving method" for network learning, it is undoubtedly an effective way to rich student metacognitive experience. Meta-cognition training cannot be improved in a short time, must go through non-consciousness to conscious automated process. Therefore, Cultivating of metacognitive should insist on long-term seepage, subtle, and finally reach the effect of formality.

\section{E. Cultivating of creativity}

To cultivate students' innovation consciousness, first of all, we should protect students' unique personality, and give them own environment and space. In the process of teaching, students should be encouraged based on its own reality and express their inner world in unique ways. It needs a relaxed and harmonious democratic study atmosphere. Affable gentle language attitude, equality, sincere enthusiasm guidance, it is important to help students open their heart and to release their true feelings. In this kind of democracy, warm and equal environment, this would be very beneficial to cultivate students' creativity and to create a healthy psychological quality. Create imagination is the premise for creative activity, is also the student creative activities necessary. We need to use scientific and reasonable interesting teaching method to attract the student and stimulate them to the fine thing performance desire and creative impulse. Teachers should fully utilize discipline superiority, guide students to observe social and natural phenomenon to improve creation imagination. 


\section{REFLECTIONS AND PROSPECTS}

Internet has become an important part of college life, using the Internet is one important aspect of learning. In the process of using network, based on the information network transmission, understanding and analysis of the college students, it is one of the most important ways to help students in learning courses, content and methods and standards, make student's lifelong learning ability .online learning college has become an important part of students life. Through online learning mode, can reduce the traditional learning methods of reservoir pressure, sharing more outstanding teaching resources, improving learning resources, and build a good learning environment, improve the network of college teaching level, promoting the construction of information. To cultivating of students' online learning ability is a long-term concern of higher education.

\section{REFERENCES}

[1] Weimin Yang. The status and development of online learning. [D]. northwest normal university.2007..

[2] XinXian Zhang. Network learning behavior research [J]. Exam weekly. 2007(11)

[3] Kekang He, WenGuang Li. Education technology.[M]. Beijing: Beijing normal university press. 2009.

[4] LiGong Zhou. Network of research learning condition of learner autonomy in Beijing university education network _ institute for Chinese learners of the case.[J]. China Educational Technology. 2010(6).

[5] Fang Lang . College English teaching network effect evaluation and online learning behavior research[D]. wuhan university, 2005.

[6] Aiping Xiao. Network learners online learning situation _ factors and countermeasures study [J]. open education research, 2009(1).

[7] Wanyi Zhang. Open education undergraduate students online learning situation investigation and analysis [J]. Distance education in China. 2002(9). 